\title{
Effect of Self-efficacy, Motivation and Anxiety on Online Academic Performance
}

\author{
Ivor D’Souza ${ }^{1 *}$, Dr Akriti Srivastava ${ }^{2}$
}

\section{ABSTRACT}

As the number of online-learning users continues to increase, there is a need to understand the Effect of Self-efficacy, Motivation and Anxiety on Online Academic Performance. Through the online learning process, students can access the given information of teachers at any time on the respective online platform. The study aims to find out the Effect of Selfefficacy, Motivation and Anxiety on Online Academic Performance. It is comparatively more convenient in the current situation, because of the pandemic; every educational institute follows this learning method for properly giving education or lessons to their students. The study included 150 participants studying various courses at an Indian University. The mean age of participants was 19 years. The study consisted of 3 scales, the academic self-efficacy scale, the academic motivation scale and the state trait anxiety inventory. The researcher carried out a descriptive study to identify the aim of the study. Independent sample t-test and Mann-Whitney $U$ test were carried out and the results of the study were analysed for the mentioned hypothesis. The study found that the mean scores of academic performances dropped in the individuals with low self-efficacy. Also, the mean scores of academic performances dropped in the individuals with low motivation. These differences were not significant. However, it was found out that the individuals with high anxiety saw a significant drop in their academic performances. Hence the study shows that anxiety had a great effect on the levels of academic performance of students.

Keywords: Self-Efficacy, Motivation, Anxiety, Online Academic Performance, Descriptive Study odern technological advances have led to an easier internet access that shows an increase in online learning compared to conventional learning environments. Online learning offers various learning experiences with technology, that provides accessibility, connectivity, flexibility and the ability to advance interactions between students. As the number of users of online learning continues to increase, it is necessary to understand how these students can best apply these learning strategies to attain academic success in the online environment. Self-efficacy is concluded on the basis of research which

\footnotetext{
${ }^{1}$ BSc Psychology (Honours), School of Business Studies and Social Sciences CHRIST (Deemed to be University), Bangalore, India

${ }^{2}$ Assistant Professor, Psychology Dept., (BGR)School of Social Sciences, Bannerghatta Road Campus, India *Corresponding Author

Received: May 24, 2021; Revision Received: June 20, 2021; Accepted: June 30, 2021

(C) 2021, D'Souza I. \& Srivastava A.; licensee IJIP. This is an Open Access Research distributed under the terms of the Creative Commons Attribution License (www.creativecommons.org/licenses/by/2.0), which permits unrestricted use, distribution, and reproduction in any Medium, provided the original work is properly cited.
} 
is the belief in the ability to organize and perform the actions necessary to produce specific results.

Self-efficacy decides the level of motivation that is reflected in the amount of effort that is put into an effort and the time devoted in a difficult situation. If people have a very low level of self-efficacy in relation to a task, they are comparatively less likely to work hard and get the task done. Research results show that self-efficacy is a much more better indicator of academic achievement than other cognitive or affective processes. Therefore, self-efficacy is critical for learning and performance (Hodges, 2008). Student self-efficacy seems particularly important in challenging learning environments, such as online learning, where students do not have the opportunity to interact with others and, as a result, can become socially isolated. Furthermore, the dropout rate among students in online learning environments is higher than in traditional learning environments. The dropout rate is also related to a lack of self-efficacy (Bates \& Khasawneh, 2007). Understanding self-efficacy in online learning is key to improving online education, which can be a key component of academic success in distance education.

In recent times, distance education or online learning environments have enlarged to ease the processes of learning in different fields and different levels of proficiency or knowledge. One of the subjects which have gained the most interest is how to improve academic success or learning outcomes. The causal impact on self-efficacy's academic performance is one of the key issues that have been elevated in educational research. The causality influence of confidence becomes much more important as researchers are trying to figure out whether one's self-confidence is the major cause of academic performance or is that success embedded primarily in the students' extraordinary commitment and skills (Yusuf, 2011, p. 2623). Self-efficacy as a motivation promotes grit while faced with challenges, strengthens deliberate actions, facilitates long-term view, promotes self-regulation, and enables selfcorrecting if appropriate. On the other hand, Increased anxiety levels cause the students lower performance in an exam situation.

Based on a socio-cognitive motivation perspective, this research's key aim is to incorporate the influence of self-efficacy, motivation, and anxiety on academic performance. Selfefficacy values affects the amount of anxiety and stress that people feel when they partake in a conversation, potentially as students engage in a course. While there is theoretical evidence for showing the positive impact of self-efficacy values on students' well-being and course satisfaction, the motivating process that facilitates the self-efficacy-students' relationship of satisfaction is still a problem that is to be solved. In general, it is crucial to know about the variables that affect online learning or academic performance, which include motivation, self-efficacy, and anxiety, because these are effective in academic success.

\section{Variables}

\section{Academic Self-efficacy}

It refers to "beliefs in one's capabilities to organize and execute the courses of action required to produce given attainments" (Bandura, 1997). Dependency directly influences the self-efficacy level on using online technologies in controlling the online learning experiences. Independent students have generally preferred online technology for their learning to create a significant impact on their self-efficacy level, whereas dependent students have not got the chance to select online technologies for their learning process that also adversely impact their self-efficacy (Monica DeTure, 2004). Self-efficacy is majorly 
believed to be a crucial component in successful online learning; however, most existing studies of online self-efficacy mainly focus on the computer.

The idea of specific SE was at first suggested in his social cognitive theory. SE can be categorized as an individual's belief in their potential to succeed in a different condition or achieve a specific mission. While the concept of self-esteem is quite similar, self-esteem requires an emotional evaluation of individuals of own value. However, SE contains an individual's ability assessment to attain a self-belief or goal. For instance, in an academic state, it can be expected that self-belief learners have a higher learning motivation, caused in higher academic performance, as those learners are certain that they have the capability to achieve their objective. It is recognized that SE is affected by age, domain, and gender. Academic self-efficacy (ASE) varies between age, gender, as well as domains such as social sciences and mathematics. Dependency specifically affects the self-efficacy level that uses online tools in managing the online learning experiences. Independent students have usually chosen online technology to produce a substantial effect on their self-efficacy level. At the same time, dependent students haven't yet got the chance to pick online technologies for their learning process, which also negatively affects performance.

From a theoretic viewpoint, SE can be improved by the practice of mastery, detecting others succeed, and external persuasion like overt motivation. In addition, physiological variables have been believed to affect SE. For instance, insights of fatigue, fear, and pain may have a noticeable, harmful impact on SE. In the identical study, genetic factors described SE variation of $75 \%$ (Yokoyama, 2019, pp. 1-2).

Identifying self-efficacy in the social-cognitive theory context, self-efficacy as a motivational orientation promotes grit while faced with difficulties, strengthens deliberate behavior, facilitates long-term vision, promotes self-regulation, and provides for selfcorrecting if appropriate. Numerous analyses have offered self-efficacy as a consistent predictor of performance and motivation, one that doesn't change according to the environment, time, and different communities. The students that keep superior abilities show better performance and obtain superior evaluations. These students seemingly possess less anxiety and higher self-efficacy. ASE at higher scores are more probably to cause higher academic performance levels. Further, grade effort and goals regulation are important factors in academic performance, like ASE. ASE is considered to be the most important predictor or factor for learners to achieve success in learning.

Learners gain information for their self-efficacy appraisal from their solid performances, their experiences indirectly, the encouragements they obtain from others, as well as their physiological reactions. Self-efficacy beliefs impact task choice, persistence, effort, resilience, and accomplishment. Compared to students that query their learning capabilities, and those who feel productive for a task learning or performing participate in academic selfefficacy development more keenly, work harder, keep on longer when they meet difficulties, and attain at a higher level (Meral, Colak, \& Zereyak, 2012, p. 1143).

\section{Academic Motivation}

In the following study the researcher studies the aspects of motivation using the given scale Vallerand et al(1992) which follows the tenets of self determination theory that has 3 aspects of motivation intrinsic, extrinsic and amotivation. According to the findings given by Deci and Ryan's $(1985,2000)$ construct of intrinsic motivation into three unordered subscales: 
intrinsic motivation for knowledge, intrinsic motivation toward accomplishments, and intrinsic motivation for stimulation.

In online learning, the motivation role has received substantial attention because of the student's high attrition rates in online classes. Academic motivation is an important academic success predictor and has a major influence on student learning or behavior. Researchers in informative studies have used diverse motivational theories to inspect motivation academicaly like expectancy-value theory, self-efficacy theory, intrinsic motivation, and goal theory. The need to satisfy individual needs is the main motivation source. Furthermore, many concepts, such as individual values, interest, desire and attitude towards an action, affect the motivation process. Thus, motivation has a structure that is multi-dimensional rather than a basic and simple one. Incidentally, each individual might have a different level of motivation (Orhan-Özen, 2017, pp. 35-36). Intrinsic motivation into three unordered subscales that are: intrinsic motivation towards accomplishments, for knowledge and for stimulation. However, there are three extrinsic motivation subscales: identified regulation, introjected regulation, and extrinsic regulation. Finally, amotivation which assesses the experience of a lack of motivation

There are various motivational factors \& scales to measure motivation of students' for a particular course, like MSLQ (Motivated Strategies for Learning Questionnaire) and Achievement Motivation Inventory. MSQL was intended to measure the motivation of college students' \& self-regulated learning associated with a particular course. It measures certain motivational factors in three constructs:

Value construct. The value construct includes intrinsic goal motivation and extrinsic goal motivation which have been discussed in detail below:

- Intrinsic Goal Orientation is the perceptions of students' of involving in a learning activity for curiosity, mastery, or challenge. Intrinsic goal orientation of high level for an academic task suggests that students believe in the task for themselves.

- High intrinsic motivation students have higher grades in the course, or higher-level intrinsic value is associated with a higher student achievement level.

- Extrinsic Goal Orientation signifies the extrinsic motives for task participation like attaining good rewards, grade, or over peers achieving competitive advantage

- Students with a high level of extrinsic goal orientation don't engage for the task itself in academic tasks.

- Task Value relates to the perception of students to what level the task is useful and important.

Expectancy construct. Expectancy construct includes the control of learning and self efficacy as discussed below:

- Control of Learning: Beliefs states that the students consider that they can achieve their struggles to absorb, and this procedure will affect positive consequences. It is positively correlated with course grades.

- Self-Efficacy for Performance and Learning ensures the standards of the capability to perform a task. Self-efficacy predicts the scores of students positively.

Affect construct. Affect construct of academic motivation involves test anxiety detailed below: 
- Test anxiety is connected to the negative thinking of students, which inhibits their success. Test anxiety is correlated negatively with the classification (Alkış \& Temizel, 2018, pp. 36-37).

\section{State Anxiety}

Studies indicated that academic achievement of students has lessened as a result of increasing the levels of state-trait anxiety (Endler, Kantor \& Parker, 1994; Batumlu \& Erden, 2007). At this point it is an important question to answer which kinds of anxiety increase during the learning process.

Anxiety is a central human emotion that contains fear and insecurity and usually happens if a person feels that the event threatens him or herself. Anxiety may also depend on the length of the disorder or features. The normal thought mechanisms are disrupted by anxiety. Rather than engaging with it, they prefer a passive approach to the material. Anxiety is the human emotion encountered by all. Students have difficulties in studying and are anxious to take tests or to make crucial life choices. Anxiety leads to students failing to perform effectively. Far away, learners' anxiety is largely a product of their life experiences and expectations. The learners in the distance tend to be fearful of failure and consider themselves strong, even unrealistic. They may have had poor educational experiences in the past and believe that distance learning education will give the same environment of disabilities as many schools have (Ajmal \& Ahmad, 2019, p. 68).

Researchers revealed that a high level of anxiety influences students' decreased attention, distraction, and thought. Researchers find that the loss of the working mind, distraction, and reasoning of students were affected by high anxiety levels. Anxiety is recognized to play a major role in student learning and development, and academic success and is considered to impact academic achievement that both encourages and encompasses it. Researchers looked at the association between anxiety and the impact of academic success within the school student. They found that lower academic acts and better anxiety were correlated with low academic attainment among high school students through greater anxiety (Vitasaria, Wahab, Othman, Herawan, \& Sinnadurai, 2010, p. 491).

\section{Online Academic Performance}

Through the online learning process, students can access the given information of teachers at any time on the respective online platform. It is comparatively more convenient in the current situation, because of the pandemic; every educational institute follows this learning method for properly giving education or lessons to their students. However, like the traditional process of learning, online classes must start within the given timeframe. Students must follow this while gaining lessons through an online learning environment. Because of technical problems, sometimes online classes may be postpon ed, which negatively impact on the students' motivation and eagerness of learning (Shea \& Bidjerano, 2010).

Online learning or distance learning environments have recently been enlarged to facilitate learning processes in different places at different levels of knowledge or skills. How to maximize academic achievement or learning is one of the themes which attracted the most attention. During the online schooling, ICT self-efficacy or other aspect has been suggested as affected. As the number of online learners rise, it is required to understand how students will best implement learning strategies to succeed in academic work in the online world. It is significantly more convenient in the current situation due to the epidemic; every educational 
organization follows this learning method for appropriately giving lessons or education to their students. Nevertheless, like the traditional learning process, online classes have to start in the given timeframe.

The flexible, interactive nature of online learning makes it extremely productive to advance careers, improve students' employability, and strengthen faculty members' preparation to operate in the modern age. Some might argue that it is better than learning based in the classroom (Peechapol, Na-Songkhla, Sujiva, \& Luangsodsai, 2018, p. 64)

\section{Significance and Scope of the Study}

In the limited literature of review conducted the current studies have found that self-efficacy is understood to be a major component in successful offline learning; however, much more research is needed to suggest that high self-efficacy shows similar results with students and their online academic performance.

Research shows that motivated learners are more likely to undertake challenging activities, be actively engaged, enjoy and adopt a deep approach to learning and exhibit enhanced performance, persistence and creativity (Ryan \& Deci, 2000b). Through the study the data will highlight how students that have a better online academic performance are either extrinsically motivated or intrinsically motivated, this data will provide a greater understanding for teachers and instructors to understand the adept way to deliver the content to their students based on the kind of motivation the student identifies with, ie intrinsic or extrinsic motivation. Anxiety while studying is a major decider of academic performance (McCraty, 2007 and McCraty, et al., 2000) and numerous studies have showed that it has a detrimental effect.

There are findings that support previous research that high level of anxiety brings about lower academic performance (Sena et al., 2007 and Luigi et al., 2007). High anxiety also shows that students have a low ability to study. High score of STAI indicates that students who have a higher score in anxiety achieve a low GPA.

However the literature is not sufficient to validate the same finding for online academic performance, hence the data obtained from this study can help fill in the research gap and validate that high trait anxiety is contributing to a low online academic performance. This study focuses on determining the influence of the main variable, i.e., self-efficacy, motivation, and anxiety, on online learning academic performance. Thus, this study will provide great insight into these variables' effects and online learning by reviewing the literature. Hence, found that ASE at higher scores is more probably to cause higher academic performance levels. Further, grade effort and goals regulation are important factors in academic performance, like ASE. ASE is considered to be the most important predictor or factor for learners to achieve success in learning. This might mean that if students' ASEs are enhanced, they can achieve higher academic performance (Yokoyama, 2019).

Research also highlights that enthusiastic learner are more likely to take on challenging activities, be vigorously engaged, enjoy as well as embrace a profound approach for learning and display improved persistence, creativity, and performance. In addition, it shows that when intrinsically motivated, external incentives are redundant and may also be counterproductive because the reward lies in performing the activity. On the other hand, extrinsically motivated students undertake tasks for reasons distinct from the activity; for instance, achieving good grades, evading negative results, or having efficacy value (like 
passing a course to achieve a degree). Instead, the activity might be seen as pertinent to a future career (Hartnett, 2012, p. 30).

Some studies have shown that the anxiety consequences during examination or test may limit the educational system's vocational or educational development promotion. It is normal for a student to feel anxious before an examination or test, but it turns out to be problematic while the anxiety level is excess. Various factors can lead to a student's anxiety level; examples contain course experience, course load perception, their incapability to manage time, beliefs, and family issues. A complex factors interplay may have formed, may cause a unique contribution to a situation, and cause anxiety. In this study, their various factors contribute to factors that influence academic performance. Students with high anxiety levels shows that they have a condensed memory span, lack confidence, lose concentration, and low cognitive power. The element can be defined as regret and anger in students if they feel anxiety in problematic situations associated with their study. Generally, anxiety with a high level is more closely related to lower performance between low-ability students.

Though the literature isn't adequate to authenticate the same finding for online learning academic performance, the data got from this study can help fill in the gap of research and authorize that high anxiety trait is lead to a low online academic performance.

\section{Research Questions}

Research Question 1 (RQ1): Is there any difference in online academic performance of students with high and low academic self-efficacy?

Research Question $2\left(\mathbf{R Q}_{2}\right)$ : Is there any difference in online academic performance of students with high and low academic motivation?

Research Question $3\left(\mathbf{R Q}_{3}\right)$ : Is there any difference in online academic performance of students with high and low anxiety levels?

\section{REVIEW OF LITERATURE}

Academic success and acquiring passing marks are among the fundamental objectives on the whole degrees of training while at the same time having positive results both for the students and instructive frameworks. Accordingly, recognizing the components affecting the students' academic achievement has at any point been one of the main worries of the scientists and instructive therapists. Furthermore, one of the difficulties looked by clinical schools. People with low self-appreciation viability will have contrary considerations and consider errand requests undermining not as trying and consequently set low goals for themselves (Hayat, Shateri, Amini, \& Shokrpour, 2020). Students who can start their examination exercises with self-efficacy and create relevant self-learning systems are bound to advance and accomplish better because non-self-controlled students are not associated with learning measures. Subsequently, they may be exposed to any shallow information and low academic accomplishment. Reliably, broad proof from observational examination has demonstrated the impacts of self-efficacy on students' academic achievements. The causal impact of "self-efficacy" on academic accomplishments is among the significant issues in the instructive examination. The causality impact of self-conviction turns out to be intriguing when specialists attempt to see if one's self-certainty is an essential driver of academic success or that success is generally established in the students' wonderful exertionbilities (Şanlı, 2021).

Student self-efficacy seems particularly important in challenging learning environments, such as an online learning environment where students lack the opportunity to interact with 
others and as a result can become socially isolated and easily lost (Cho \&Jonassen, 2009; Cho, Shen, \&Laffey, 2010).

Self-efficacy is a key competence belief in self-regulatory control processes (Schunk\& Zimmerman, 2006). Bandura (1995) defined perceived self-efficacy as "the beliefs in one's capabilities to organize and execute the courses of action required to man- age prospective situation". In other words, self-efficacy is the belief of the capabilities of what one can do in a specific domain. Self-efficacy impacts task choice, effort, persistence, and achievement. It also influences academic motivations, learning, and achievement (Schunk \&Pajares, 2002). From this point of view, students with positive self-efficacy toward learning in online courses are usually more motivated and perform better in these courses. Studies indicated that internet self-efficacy positively correlates with or predicts students' performance in web-based learning environments (DeTure, 2004; Joo, Bong, \& Choi, 2000; Thompson, Meriac, \& Cope, 2009).

Learning motivation is based on the beliefs in one's capabilities and the evaluations of the learning environment. The evaluation of ability and learning environment helps students to select a learning task and learning environment that are best suited to their abilities (Wood \& Bandura, 1989). Students seeking to learn online require skills in information technology and computer self-efficacy (Compeau\& Higgins, 1995). Barbeite and Weiss (2004) demonstrated that computer self-efficacy can be used to predict student computer use and whether they will learn well in computer-based courses. Potosky (2002) indicated that a high degree of self-efficacy transforms into increased motivation to learn.

Liaw (2002) showed that the internet self-efficacy of college students influences learning performance, and as internet self-efficacy increases, motivation to use the internet increases, as does learning performance. Tsai and Tsai (2003) also indicate that students with higher internet self-efficacy perform better than those with low internet self-efficacy in the webbased learning task. Law, et al. (2010) reported that three motivating factors, namely, individual attitude and expectation, challenging goals, and social pressure and competition had a significant and positive relationship with self-efficacy. Song and Keller (1999) investigated the relationship between self-efficacy and motivation, and found that selfefficacy also influences the motivation of learners. The internet has been widely applied as a learning tool, fully integrated within a wider learning context. Under these circumstances, the concept of internet self-efficacy was proposed and it has been found that high internet self-efficacy has a positive influence on one's expectation concerning learning performance in online contexts (Compeau\& Higgins, 1995). Learner satisfaction has been considered a key factor in an online learning context. Sachs and Hale (2003) claimed that online learning providers should put more focus on learner satisfaction in measuring the impact of online programs.

Recent researches have pointed out that mechanisms of learning and recalling are related to relatively permanent changes in the nervous system. Substances emitted in the brain during high level of concern prevent the protein chain, which is essential for learning, to be built, and therefore, increases the concern level and restricts learning partially causing failure (Baltaş, 2004). Although a certain level of concern is necessary for learning, it is vitally important to adjust its ratio (Ankay, 1990).

The term self-efficacy refers to "beliefs in one's capabilities to organize and execute the courses of action required to produce given attainments" (Bandura, 1997). Self-efficacy, the 
learner's belief about his or her ability to perform a given task, is the personal aspect that accounts for why a person engages in the task. Individual behavior is not directly affected by personal variables; rather those personal variables affect individuals to the extent that they influence correspondence.

Motivated students have a much higher achievement, a better understanding of curriculum, a greater satisfaction with school, and lower dropout rates. Motivation affects all aspects of schooling including relationships with teachers and peers, help-seeking, and effort. Motivation reduces steadily from elementary to middle school to high school.

The feeling is an abstract status joined by physiological responses and reactions to certain conditions, activities, and occasions. Alk1 and Temizel (2018) characterize scholastic feelings as straightforwardly identified with accomplishments, exercises, and results. This term was first utilized by Alk1 and Temizel (2018) in the field of the training ordered into positive (satisfaction, pride, trust); negative (weariness, outrage, tension); actuating (delight, pride, outrage); and deactivating (disgrace) feelings. Feelings have a complex relationship with psychological, inspirational, and conduct measures, particularly in the homeroom and instructive settings, on the whole, instructive circumstances (previously, during, and in the wake of going to the study hall, considering and testing), and in scientific settings, as knowledgeable by the students (Alkış \& Temizel, 2018) Besides, a few researchers have considered feelings to be a major factor straightforwardly or by the implication related with students' that are accomplishments; fulfilment; physical and emotional well-being; inspiration; learning systems; academic sources; self-coordinated learning; nature of educator student connections; class training; fixation; data handling, putting away, recovering, and learning; and like this scholarly accomplishment. Ajmal and Ahmad (2019) demonstrated that wonderful positive feeling like pleasure decidedly affect academic accomplishment. Despite what is generally expected, upsetting deactivating feelings like weariness can decrease our inspiration and upset information handling, showing the bad impact of such feelings on educational accomplishment.

Qudsyia and Putri (2017) tracked down a critical connection between the students' optimistic feelings and performance. Qudsyia and Putri (2017) uncovered that positive enacting feelings like happiness, expectation, and pride have a huge association with the learners' midterm test scores. By and large, past research showed that positive feelings like satisfaction, expectation, and pride are indicators of academic accomplishment. Scholastic self-viability is the significant element affecting academic performance. Scholarly selfefficacy alludes to the scholars' convictions and mentalities to their capacities to make academic progress, just as faith in their capacity to satisfy scholarly errands and the materials' effective learning. Gbollie and Keamu (2017) stated that self-efficacy convictions lead to an incredible performance by expanding responsibility, try, and steadiness. The students with undeniable degrees of self-efficacy property their disappointments to bring down endeavours instead of bringing down capacity. Those with low "self-efficacy" quality their inability to their low capacities (Yang, Zhang, Kong, \& Wang, 2020). Consequently, it can affect the determination of tasks and relentlessness while responsible for them. Students with small self-efficacy will undoubtedly fear completing their endeavors, evading, conceding, and give them soon.

Conversely, Sharififard and Asayesh (2020) stated that those with significant degrees of self-efficacy are bound to depend on themselves when confronted with multifaceted issues to discover an answer for the issue, just as showing restraint during the interaction, putting 
forth more attempts, and enduring longer to beat the difficulties. Along these lines, it appears to be that self-efficacy is perhaps the main element in the students' scholarly achievement. For instance, Qudsyia and Putritracked down that the students' "self-efficacy" in the principal year of college is a solid indicator of their upcoming performance.

Different investigations have shown that academic self-efficacy considerably affects the students' learning, inspiration, and scholarly performance. Self-efficacy convictions incorporate people's airs towards what they think they can do and what assignments they can achieve during the time spent learning. Yokoyama (2019) estimated that self-efficacy convictions influence students' objectives, inspiration, and nervousness; along these lines, in an investigation focusing on changes in inspiration and uneasiness, it appears to be essential to likewise take advantage of potential changes in students' self-efficacy levels. Research into self-efficacy and unknown dialect learning has begun to thrive with spearheading work. In their outline of self-efficacy research regarding second language learning, Hayat, Shateri, Amini, and Shokrpour (2020) affirm that most investigations have concentrated on selfefficacy and language learning methodologies, language nervousness, and accomplishment utilizing correlational plans. They additionally call attention to that the manners by which self-efficacy creates have barely been analyzed. One part of self-efficacy that applies to the current conversation, keeping in touch with self-efficacy, has been explored by Yang, Zhang, Kong, \& Wang (2020), who recommends a few different operationalizing thinking waysof self-efficacy. By this proposition, in the current investigation, we conceptualize thinking of self-efficacy as 'surveying the certainty that students need to finish composing undertakings (Yang, Zhang, Kong, \& Wang, 2020). Past research has demonstrated composing efficacy to be decidedly connected with students' premium and extended exertion, just as with performance, and adversely connected with composing tension.

Two outstanding investigations that have started to fill the gap in research on thinking of self-efficacy and its improvement over the long run are those by Saade ans Kira (2017). Utilizing a trial configuration, Hayat, Shateri, Amini, and Shokrpour (2020) tracked down that bogus novice French students' self-efficacy improved altogether considering the standards' five objective territories Foreign Language Learning subsequently to having partaken in project-based learning. Sharififard and Asayesh (2020) additionally explored the difference in students' self-efficacy by focusing on second language writing in a moderate French class utilizing worldwide reenactment. Students' self-appreciation efficacy explicitly identified with piece composing sub-abilities in an unknown dialect expanded in the worldwide recreation study hall. However, their general self-efficacy convictions about their capacities to finish composing assignments did not change. As perAlkış and Temizel (2018), self-efficacy is a solid source that helps individuals shield themselves from mental stressors. Somebody whose self-efficacy convictions are low can encounter more uneasiness than those whose self-efficacy convictions are high. It is because that the given task is seen as a danger when the person's self-efficacy convictions are low and as a test when the person's self-efficacy convictions are high. The increment in the assignment's significance for the individual can bring about the insight that the individual has a great deal to lose when they do not finish the task effectively (Alkış \& Temizel, 2018). Individuals' self-efficacy convictions reflect the degree to which they see themselves as effective when given an assignment. In this sense, a given task turns into the source of terrorizing and nervousness for the individuals who accept that effectively finishing the task is significant for them, yet who do not see that they have the ability to finish the task. 
In contrast, some of the studies have revealed no significant relationship between ASE and academic performance (e.g., Crippen et al., 2009; Cho and Shen, 2013, Gebka, 2014). Operationalization of ASE, the timing of measurement, and cultural differences have been proposed as reasons (Honicke and Broadbent, 2016). Currently, it has been assumed that the ASE is one of the important factors or predictors for learners to achieve learning success. This may mean that if a student's ASE is enhanced, then the student may be able to achieve higher academic results, grade goals and effort regulation are strong factors in academic performance, similar to ASE.

Honicke and Broadbent (2016) noted that effort regulation, deep processing strategies, and goal orientation have moderated the relationship between ASE and academic performance. In contrast, some of the studies have revealed no significant relationship between ASE and academic performance (e.g., Crippen et al., 2009; Cho and Shen, 2013; G ebka, 2014). Operationalization of ASE, the timing of measurement, and cultural differences have been proposed as reasons (Honicke and Broadbent, 2016).

In the current scenario, it has been stated that ASE is one of the main important factors or predictors for learners to gain learning success. This may mean that if a student's ASE is enhanced, the student may be able to achieve higher academic results. Evaluation objectives and effort guidelines are solid components in scholastic execution, like scholarly selfproductivity. Honicke and Broadbent (2016) noticed that effort guidelines, profound preparing techniques, and objective direction had directed the connection between ASE and scholastic execution. As well-known, objective-related viewpoints, grade objectives and objective direction, and effort guideline have been begining by two of three metaexaminations to be one of the most grounded factors that influence scholastic execution other than scholarly self-effectiveness (Pascoe \& Hetrick, 2020).

Moreover, albeit just a scarcity of longitudinal examinations has been led on the connection between ASE and scholastic execution, the latest meta-investigation has uncovered that a higher ASE improves scholarly execution longitudinally and the other way around. Interestingly, a portion of the examinations has uncovered no significant connection between ASE and scholarly performance. Operationalization of academic self-effectiveness, the timing of estimation, and social differences have been planned as reasons. It has been accepted that ASE is perhaps the main variable or indicator for students to make learning progress. It may imply that if an understudy's ASE is upgraded, the understudy might have the option to accomplish higher academic outcomes.

Motivation is an essential part of student achievement. It consists of both internal and external factors that encourage people to be persistently interested in and dedicated to their work, career, or topic or to make an effort to achieve a milestone. According to Pascoe and Hetrick (2020), motivation reveals why people want to do something, how hard they will work to do it, and how long they will help the movement. In a nutshell, inspiration is the force that propels you forward, makes all the difference in your life, and determines where you want to go (Gbollie \& Keamu, 2017). According to Saade and Kira (2017), students with perfect inspiration have an advantage because they have multipurpose mentalities and methodologies, such as maintaining inborn premium, an "objective" environment, and selfchecking. Furthermore, motivational stimuli work in tandem with cognitive, emotional, and rational variables to agitate self-control. Furthermore, motivational convictions are captious for students' academic success because they can determine the extent to which students can accept, value, expend effort, and express interest in the task. Self-viability, for example, has 
an effect on how students behave, learn, empower themselves, and act. According to the study, students' critical thought execution is fully correlated with their self-adequacy beliefs. For example, inspiration gained from eye-to-eye activities is a strong predictor of final grades. In a mixed learning environment, a significant positive relationship between selfadequacy and course feedback was discovered. Qudsyia and Putri (2017)expressed that online learning is not appropriate for all students; along these lines, their academic performance could change as indicated by the learning climate. The examination directed by Gbollie and Keamu (2017) uncovered that student went against the possibility that educating in an e-learning setting was steady of learning.

Anxiety is a common human emotion that affects all. Students have problems with their exams and feel restless when taking tests or making important life decisions. There is proof in the literature that shows there is a negative relationship between fear and understudy performance. Anxiety and accepting significant intellectual and enthusiastic distance learning outcomes have a negative association (Asayesh, Hosseini, \& Sharififard, 2016). The clear distinction between face-to-face and distance learning and natural factors that influence distance students to have anxiety about distance learning is almost certain. Gbollie and Keamu (2017) put it compactly; anxiety makes students reliably fail to meet expectations. Distance students' anxiety derives mostly from their context and the assumptions/presumptions they make as a result.

On the one hand, distance students fear rejection, but on the other hand, they may have unrealistic expectations of themselves. They may have had hostile teaching experiences and agree that distance learning education may provide the same trying to sabotage the learning environment that many schools do. During educational exercise sessions, social anxiety has a significant effect on performance. These anxiety issues influence performance, causing a weakening in their investigations and significant issues among distance students (Ajmal \& Ahmad, 2019). To take care of this issue present investigation gave a few bits of knowledge on the advancement of distance training in Pakistan and did an itemized examination of distance schooling practice. Finally, the paper's primary purpose has been committed to examining elements of anxiety that influence distance-learning students' performance.

A bunch of students who are concentrating in distance organizations faces a ton of issues and anxiety factors. Examination members of this investigation felt anxiety because of issues looked at the hour of confirmation, while getting a plan for affirmation, finding a bank to store charges, receipt of books, deficiency of time given to prepare errands, tasks, and activities, absence of normalized and quality books, absence of correspondence with mentors, helpless arrangement of feedback, communication gap among student and provincial workplaces of foundation, due dates of tasks, appreciation of tasks, evaluation system, guide comments, and their anxiety level was high, playing out a task next to each other with training, area of test focus, issues confronted in regards to tasks plan. (Yokoyama, 2019). Absence of connection with the class colleagues, absence of information and comprehension of paper design, exams plan, area of test focus. Conduct of invigilator at test focus regarding paper checking, detail marks sheets and degree, equality, and extent of degree. Saade and Kira (2017) directed an investigation to think about the relationship between anxiety and undertaking execution. It was investigated in the examination that as anxiety about school execution turns out to be more genuine, students' capacity to play out these assignments completely reduces, even as anxiety turns into a serious issue for them (Saade \& Kira, 2017). In this way, students' presentation tumbles down progressively. Students in this situation might be overpowered by the errands they face and stress over their 
capacity to achieve these assignments and that they essentially cannot finish the undertaking adequately. The perceptions made in the above investigations imply that there is an alternate level of connection between anxiety levels and execution.

The self-adequacy has an impact on accomplishment motivation and self-learning systems on members' academic achievement. The examination of immediate and roundabout outcomes showed the meditational part of self-viability on accomplishment motivation and learning systems. The most upraised measurable critical influence was between that of respondents' self-viability and CGPA, proposing not one or the other, the accomplishment motivation, nor was the learning methodologies the most grounded reason for the respondents' academic accomplishment. The above discoveries were like the current writing on self-adequacy, accomplishment motivation, learning techniques corresponding to the student's academic accomplishment. Students who can start their examination exercises with self-efficacy and create relevant self-learning systems are bound to advance and accomplish better. Self-efficacy convictions lead to the people's incredible performance through expanding responsibility, try, and steadiness. The students with undeniable degrees of selfefficacy property their disappointments to bring down endeavors instead of bringing down capacity. Those with low self-efficacy quality their inability to their low capacities. Most investigations have focused on the relationship of self-efficacy and language learning methodologies, language nervousness, and accomplishment utilizing correlational plans. Students' self-appreciation efficacy explicitly identified with piece composing sub-abilities in an unknown dialect expanded in the worldwide recreation study hall. However, their general self-efficacy convictions about their capacities to finish composing assignments did not change.

\section{Rationale for the Study}

The research work puts a spotlight on the identification of the effect of self efficacy, anxiety level and motivation of students on online academic performance. Studies have shown that self-efficacy of students affect their online academic performance, which is considered as a useful predictability factor for student success. However, most of the past studies fail to find out the effect of anxiety level and motivation on online learning of students'. Therefore, this study emphasizes on finding the significant connection between the online learning environment and students' anxiety level along with self-efficacy and motivation.

The extant literature offers overpowering help for the connection between self-efficiency and academic performance. Nonetheless, the writing that examines the communications and pathways by which this relationship exists is more mind-boggling. It is credited to a limited extent to the absence of miserliness in the models that have been tried, the various blends of factors that have been utilized in model turn of events, and the exploratory, non-causal nature in which quite a bit of this research has occurred (Yang, Zhang, Kong, \& Wang, 2020). Despite applicable research on the connection between self-efficacy and achievement, there is no accessible research audit that has examined the impact of selfefficacy on academic achievement, including the advocacy and leadership components that are believed to influence achievement. relationship. In a university town. Also, although the most latest study is only five years old, it did not take into account pre-AAP measures of academic achievement, which were concentrated close to self-efficacy indices. Although GPA is a generally used performance measure among college tests that examine the connection between self-efficacy and academic achievement, it is crucial to consider the effect that other outcome measures may have on this relationship. Furthermore, important ongoing writing has not taken into account research findings outside of Europe or North 
America, which may be predisposed to the introduction of discoveries, especially given the distinction in tertiary construction outside of these areas (Sharififard \& Asayesh, 2020). Given the abundance of accessible research and the accentuation that self-efficiency has gotten in instructive research exploring scholarly accomplishment, it is important to distinguish patterns in research discoveries and give future research suggestions.

\section{METHODOLOGY}

Objectives

- To find out if there is any difference in online academic performance of students with high and low academic self efficacy

- To find out if there is any difference in online academic performance of students with high and low academic motivation

- To find out if there is any difference in online performance of students with high and low anxiety level

\section{Hypotheses}

$H_{1}$ Students with high academic self-efficacy would be better in online academic performance than students with low academic self-efficacy

$\mathrm{H}_{2}$ Students with high academic motivation would be better in online academic performance than students with low academic motivation

$\mathrm{H}_{3}$ Students with low anxiety levels would be better in online academic performance than students with high anxiety levels

\section{Research Design}

The study was based on the descriptive research design. The study that was conducted by the researcher was a quantitative research method that attempted to collect quantifiable details for statistical analysis of the population sample. In the said research that was conducted, none of the variables were influenced in any way. This used observational methods to conduct the research. Hence, the nature of the variables or their behaviour was not in the hands of the researcher.

The study provided scope for further research as the data was collected and analyzed from descriptive research using different research techniques.

\section{Operational Definition}

Academic Self-efficacy: Academic self-efficacy states the theory that a person's conviction that they can successfully reach at a specific level in a certain academic subject area. Individuals normally pick activities and tasks in which they feel good and avoid the ones that do not suit them. Given that the current studies focus on students' self-efficacy and its contribution to academic performance on written tests, the change from offline to online mode of learning may have an major impact on their academic performance, hence proving how students academic self-efficacy and their respective online academic performance will provide scope for further research upon obtaining the results.

Academic Motivation: Academic motivation will be studied with the help of the academic motivation scale given by Robert J. Vallerand (1992) which measures the motivation level of students toward learning. It is based on the tenets of self determination theory that talks about the three aspects of motivation namely being intrinsic motivation, extrinsic motivation and amotivation of an individual. 
Anxiety: For this study, anxiety will be studied as state anxiety, which will be assessed by STAI (Speilberger, Gorsuch, Luchene, Vagg, \& Jacobs, 1983), which was a 40-item selfreport scale that evaluate separate dimensions of "state" and "trait" anxiety. The state anxiety measure will be used for this which would address how the individuals generally feel by rating themselves on a four-point scale: almost never, sometimes, often, or almost always.

\section{Tools}

The General Self-Efficacy Scale (GSE) Schwarzer, R., \& Jerusalem, M. (1995): Responses are made on a 4-point scale. Sum up the responses to all 10 items to yield the final composite score with a range from 10 to 40 .

Academic Self-Efficacy Scale is prepared assessing the academic self-efficacy of secondary school students based on the Self-Efficacy theory of Albert Bandura (1977) who placed it within the framework of Social Cognitive theory.

The perceived self-efficacy construct reflects an optimistic self-confidence (Schwarzer, 1992). It is the belief that one can perform new or difficult tasks or face adversity, in various areas of human functioning. Perceived self-efficacy facilitates goal setting, investment of effort, persistence in the face of barriers, and recovery from setbacks. It can be considered a positive resilience factor. Ten objects are designed to explore this construction. Each element refers to successful coping and implies a stable internal allocation of success. Perceived self-efficacy is an operational construct, that is, it is related to subsequent behavior and, therefore, is relevant for clinical practice and behavior change.

Academic Motivation Scale (AMS-C 28): Academic Motivation Scale (AMS) is one of the majorly used instruments to measure the motivation level of students toward learning. The scale consisted of 28-item seven-point Likert scales. The scale had shown a very high level of internal and external consistency in numerous researches.

The scale was based majorly on the tenets of self-determination theory. The outline of it was to assess an individual's academic motivation if intrinsically or extrinsically driven with 28 questions.

State-Trait Anxiety Inventory: The State Trait Anxiety Inventory (STAI) is a commonly used measure of state trait and anxiety (Spielberger, Gorsuch, Lushene, Vagg \& Jacobs, 1983). Form Y, its most popular version, has 20 items for assessing trait anxiety and 20 for state anxiety.

Internal consistency coefficients for the scale have ranged from .86 to .95 ; test-retest reliability coefficients have ranged from .65 to .75 over a 2 -month interval (Spielberger et al., 1983).

\section{Sample}

Sample Size: The sample size for this study included 150 participants.

Sample Description: Students are the targeted sample of the study because the study has an intention to find out the impact of the student's self-efficacy, motivation, and anxiety traits on their online academic performance. The study was set between the age group of 18 to 24 years for this project, students within the age group can state their feelings and state their anxiety and motivation for the same in a concise manner. 
Sampling Technique: The sample was identified through non probability sampling. By applying purposive sampling, the researcher selected the candidate for the study for amending research problems.

Inclusion Criteria: Students that belonged to the age group of 18 to 24 . Students were actively engaged in an online learning environment at the time of the data collection.

\section{Procedure}

Through survey method and online forms the researcher will structure the data collection process. Students between the age group of 18 to 24 are the target population for this study, who have the knowledge to access the online platform for their education purpose. Based on a mentioned scales that is Academic Self-Efficacy Scale for Students, State-Trait Anxiety Inventory, and Academic Motivation Scale the scholar will gather quantitative data from the population. A total population of 150 students will be selected based on a purposive sampling technique who will further be subjected to the aforementioned scales for analyzing set hypotheses and reaching the research objectives.

\section{Data Analysis}

The researcher had conducted shapiro wilk's test to find the normality of the data. Shapiro Wilk normality test was done with respect to the variables of academic performance, academic self-efficacy, motivation and anxiety as selected by the researcher.

Since the significance value for the normality test is 0.05 . The p-value for the Academic Performance scale was noted to be $.0001<.05$, hence it is not normally distributed. Since the other three variables were studied as categorical variables which are not of a normal distribution, the Shapiro - Wilk Test of Normality was not done for them.

Therefore, the data collected by the researcher was not normally distributed across all variables. This resulted in the use of non-parametric data tests for the analysis of the collected data. As the data was not normally distributed, Mann-Whitney U Test was used to establish a relationship with the four variables of the study.

\section{Ethical Considerations}

Informed Consent: The participants had been informed of the nature and objective of the study. The participation of the participants was voluntary. They were informed about the right to withdraw from the study at any time along with their information.

Confidentiality: The participants' information was kept confidential and was used for research purposes only. The same was informed to the participants.

Voluntary participation: Participants were informed that all their data would remain anonymous and will be viewed only by the author in its raw form. They were told that at any time they could withdraw from the study with no consequences.

\section{RESULTS \& DISCUSSION}

The data was obtained from students, between a wide age range of 18-24 years. The sample size was 159 in total, out of which 64 participants identified as males, 95 as females mostly belonging to urban or semi-urban cities. 
Table 1 Descriptive Statistics for Study Variables

\begin{tabular}{llllll}
\hline & Minimum & Maximum & Mean & $\begin{array}{l}\text { Standard } \\
\text { Deviation }\end{array}$ & Variance \\
\hline Academic Performance & 41 & 95 & 74.3365 & 11.27027 & 127.019 \\
Self-Efficacy & 15 & 40 & 30.1006 & 5.05689 & 25.572 \\
Academic Motivation & -11.46 & 13.58 & 4.3831 & 4.59749 & 21.137 \\
State Anxiety & 20 & 78 & 49.3836 & 12.83823 & 164.82 \\
\hline
\end{tabular}

Table 2 Shapiro-Wilk normality test

\begin{tabular}{l|llll}
\hline Tests of Normality & & & & \\
\hline & Shapiro-Wilk & & & \\
& Statistic & df & & Sig. \\
& 0.965 & 159 & 0.001 & \\
Academic_Perf & & & & \\
$\begin{array}{l}\text { a Lilliefors Significance } \\
\text { Correction }\end{array}$ & & & & \\
\hline
\end{tabular}

Shapiro - Wilk normality test was done with respect to the variables of academic performance, academic self-efficacy, motivation and anxiety as selected by the researcher. The significance value for the normality test is 0.05 . From the above table, it can be seen that the p-value for the Academic Performance scale is .0001<.05, hence it is not normally distributed. Since the other three variables were studied as categorical variables which are not of a normal distribution, the Shapiro - Wilk Test of Normality was not done for them. Therefore, the data collected by the researcher was not normally distributed across all variables. This resulted in the use of non-parametric data tests for the analysis of the collected data.

As the data was not normally distributed, Mann-Whitney U Test was used to establish a relationship with the four variables of the study.

\section{Academic Performance and Academic Self - Efficacy}

The relationship between academic performance and academic self - efficacy was studied through the Mann - Whitney U test, the results of which have been discussed below.

Table 3 Test Statistics for Mann Whitney $U$ Test between variables academic performance and academic self - efficacy

\section{Test Statistics ${ }^{\text {a }}$}

\begin{tabular}{ll}
\hline & Academic_Perf \\
Mann-Whitney U & 1745.5 \\
Wilcoxon W & 2123.5
\end{tabular}




\begin{tabular}{ll}
\hline Test Statistics $^{\mathrm{a}}$ & \\
\hline $\mathrm{Z}$ & -0.168 \\
Asymp. Sig. (2-tailed) & 0.867 \\
Exact Sig. (2-tailed) & 0.869 \\
Exact Sig. (1-tailed) & 0.434 \\
Point Probability & 0.001 \\
a Grouping Variable: Self_eff & \\
\hline
\end{tabular}

As seen through the Test Statistics, Mann Whitney U Test also called the Wilcoxon test for independent samples for non-parametric data was used to understand the relationship between the two. Academic self efficacy was categorised into two groups being high and low. High academic self efficacy were individuals who had scored above 25 and low academic self efficacy were individuals who had scored 25 or below. It was seen that the value of the Mann Whitney U Test is 1745.5 at a significance level of 0.869 which is more than 0.05 , thus we concluded that our differences are not statistically significant.

Table 4 Ranks Table for Mann Whitney $U$ Test between variables academic performance and academic self - efficacy

\begin{tabular}{lllll}
\hline Ranks & & & & \\
\hline & Self_eff & N & Mean Rank & Sum of Ranks \\
& $\begin{array}{l}\text { 1 (High } \\
\text { Academic_Perf }\end{array}$ & & & \\
& S.E) & 132 & 80.28 & 10596.5 \\
& 2 (Low & & & \\
& S.E) & 27 & 78.65 & 2123.5 \\
& Total & 159 & & \\
\hline
\end{tabular}

As seen through the ranks table, the first group being students with high academic selfefficacy have higher academic performance as compared with the second group of students with low academic self-efficacy. As one can see, the mean rank for the first group of students stands at 80.28 while for the second group stands at 78.65. However, since the difference is not statistically significant, one can assume there is not much difference in the academic performance of those with high and low self - efficacy. Thus, we reject Hypothesis $\mathrm{H}^{1}$ which states that students with high academic self-efficacy will be better in online academic performance than students with low academic self-efficacy.

Self efficacy refers to faith in one's capabilities and is directly influenced by the perception of control students have over their online learning experience. Higher self efficacy promotes motivation, allows one to focus on their abilities which help them in achieving a goal, and leads to regulation of behaviour. It is perceived as an accurate predictor of academic performance wherein students with higher self efficacy perform better. This is consistent with the results of the study, however, since the difference was not statistically significant, it 
can be assumed that even though self efficacy has an impact, it is highly influenced by other factors such as intelligence, achievement, and self -regulation which were not studied.

\section{Academic Performance and Academic Motivation}

The relationship between academic performance and academic motivation was studied through the Mann - Whitney U test, the results of which have been discussed below.

Table 5 Test Statistics for Mann Whitney $U$ Test between variables academic performance and academic motivation

\begin{tabular}{ll}
\hline Test Statistics $^{\mathbf{a}}$ & \\
\hline Mann-Whitney U & Academic_Perf \\
Wilcoxon W & 2029 \\
$\mathrm{Z}$ & 10157 \\
Asymp. Sig. (2-tailed) & -0.013 \\
Exact Sig. (2-tailed) & 0.99 \\
Exact Sig. (1-tailed) & 0.991 \\
Point Probability & 0.495 \\
a Grouping Variable: Motivation & 0.001 \\
\hline
\end{tabular}

As seen through the Test Statistics, Mann Whitney U Test also called the Wilcoxon test for independent samples for non-parametric data was used to understand the relationship between the two. Academic Motivation was studied through self -determination which categorized into two groups being high and low. High academic motivations were individuals who had scored above 0 while the low academic motivation were individuals who had scored 0 and below. It was seen that the value of the Mann Whitney U Test is 2029 at a significance level of 0.991 which is more than 0.05 , thus we conclude that our differences are not statistically significant.

Table 6 Ranks Table for Mann Whitney $U$ Test between variables academic performance and academic motivation

\begin{tabular}{l|llll}
\hline Ranks & & & & \\
\hline & Motivation & N & Mean Rank & Sum of Ranks \\
Academic_Perf & 1 (High) & 127 & 79.98 & 10157 \\
& 2 (Low) & 32 & 80.09 & 2563 \\
& Total & 159 & & \\
\hline
\end{tabular}

As seen through the ranks table, the first group being students with high academic motivation have lower academic performance as compared with the second group of students with low academic motivation. As one can see, the mean rank for the first group of 
students stands at 79.98 while for the second group stands at 80.09. Since the difference between the two is not statistically significant, one can assume there is no difference in the academic performance of those with high and low academic motivation. Thus, we reject Hypothesis $\mathrm{H}^{2}$ which states that students with high academic motivation will be better in online academic performance than students with low academic motivation.

Academic motivation of individuals was studied using self -determination which assesses three different levels of motivation being intrinsic, extrinsic, and amotivation. Because of the high attrition rates in online classes, the motivation role has received a lot of attention in online learning. Academic motivation is a significant indicator of academic performance and has a significant impact on student learning and behaviour. The results of the study were not consistent with the literature, as seen by the statistically insignificant difference. Furthermore, many concepts, such as individual values, interest, desire and attitude towards an action, affect the motivation process and can be seen as a reason for the possible finding.

\section{Academic Performance and State Anxiety}

The relationship between academic performance and state anxiety was studied through the Mann - Whitney U test, the results of which have been discussed below.

Table 7 Test Statistics for Mann Whitney $U$ Test between variables academic performance and state anxiety

\begin{tabular}{ll}
\hline \multicolumn{1}{|l}{ Test Statistics $^{\mathbf{a}}$} & \\
\hline & Acade \\
Mann-Whitney U & 2493 \\
Wilcoxon W & 5496 \\
Z & -2.29 \\
Asymp. Sig. (2-tailed) & 0.022 \\
Exact Sig. (2-tailed) & 0.022 \\
Exact Sig. (1-tailed) & 0.011 \\
Point Probability & 0 \\
a Grouping Variable: Anxiety &
\end{tabular}

As seen through the Test Statistics, Mann Whitney U Test also called the Wilcoxon test for independent samples for non-parametric data was used to understand the relationship between the two. State Anxiety was categorised into two groups being high and low. High state anxiety were individuals who had scored 50 and above while the low state anxiety were individuals who had below 49. It was seen that the value of the Mann Whitney U Test is 2493 at a significance level of 0.022 which is less than 0.05 , thus we conclude that our differences are statistically significant. 
Table 8 Ranks Table for Mann Whitney $U$ Test between variables academic performance and state anxiety

\begin{tabular}{llllll}
\hline Ranks & & & & \\
\hline & Anxiety & N & Mean Rank & Sum of Ranks \\
Academic_Perf & 1 (High S.A) & 77 & 71.38 & 5496 \\
& 2 (Low S.A) & 82 & 88.1 & 7224 \\
& Total & 159 & & \\
\hline
\end{tabular}

As seen through the ranks table, the first group being students with high state anxiety (S.A) have lower academic performance as compared with the second group of students with low state anxiety (S.A). As one can see, the mean rank for the first group of students stands at 71.38 while for the second group stands at 88.1. Since the difference between the two is statistically significant, one can assume there is a large difference in the academic performance of those with high and low state anxiety. Thus, we accept Hypothesis $\mathrm{H}^{3}$ which states that students with low anxiety levels will be better in online academic performance than students with high anxiety levels.

Anxiety is an emotion which is characterized by high fear, insecurity, thoughts of worry and physiological changes. A high degree of anxiety makes it difficult for an individual to live a regular life, such as interfering with activities and social interactions. Anxiety is the most important foreteller of academic success. Students with anxiety disorders have a laid back attitude toward their studies, such as a lack of interest in learning and poor test and assignment results. Students and educators have acknowledged the prevalence of anxiety among university students. Researchers discovered that nervous people have a tougher time avoiding distractions and switching their attention from one task to the next than their less anxious counterparts. Learning, reading, recalling, and writing become more difficult as a result, impacting academic success.

\section{SUMMARY AND CONCLUSIONS}

This study aims at studying the effect of Self-Efficacy, Motivation, and Anxiety on Online Academic Performance. The sample chosen were students ranging from the age of 18-24 experiencing the shift to the online platform due to the COVID-19 pandemic. This was done specifically to maintain homogeneity across the sample. A self-reporting questionnaire of scales measuring Self-Efficacy, Motivation, and Anxiety was circulated. The academic performances on the last two online exams were also collected. The results showed that the mean scores of academic performances dropped off the sample experiencing high anxiety, low self-efficacy. There were minimal differences in the scores of academic performances due to motivation. However, two of these differences were not significant.

\section{Findings}

It was also found out that the mean scores of academic performance dropped in the individuals with low self-efficacy. Also, the mean scores of academic performance dropped in the individuals with low motivation. These differences were not significant. However, it was found out that the individuals with high anxiety saw a significant drop in their academic performances. 
Hence it can be said that anxiety had a great effect on the levels of academic performance of students. The variables for Motivation and self-efficacy could not be declared if the impact on the students was due to these variables or the other confounding variables.

\section{Implication}

Self-efficacy is thought to be a key component in effective offline learning, according to the limited literature review conducted; however, this study implicates that high self-efficacy does not have similar outcomes with students and their online academic performance. It provides the field to study other confounding variables. Motivated learners are more likely to participate in stimulating activities, be actively involved, appreciate and follow a deep approach to learning, and demonstrate improved success, persistence, and imagination, according to research (Ryan \&amp; Deci, 2000b). The data from the study will show students who perform better online are either highly or less motivated. However, since the results are not significant, it shows that there might be other confounding variables affecting the result. This information will help researchers to better understand other variables affecting the change.

Previous research has shown that students who have a higher level of anxiety receive lower grades on their end-of-semester exams. Anxiety during research is a noteworthy indicator of academic achievement (McCraty, 2007 and McCraty, et al., 2000), and several studies have shown that it has a negative impact. There are new studies that back up previous research that a high degree of anxiety is associated with poor academic results (Sena et al., 2007 and Luigi et al., 2007). Students with high anxiety have a lower capacity to learn. A high STAI score means that students with a high anxiety score have a low GPA. The current finding validates the existing literature. It also provides a better understanding for the parents, whose kids are giving online exams to focus on reducing triggers to anxiety in their home environment. It also allows the academic institutions to make the academic environment less anxious by providing ample time to study and regular breaks.

However, there is not enough literature studying antecedents of online academic performance; therefore, the findings of this study contribute to closing the research gap and confirming that high trait anxiety is a factor in poor online academic performance.

\section{Limitations}

The study's sample was not normally distributed; hence it could not be applied to a wider group of people. The participants answered a self-reporting questionnaire in the study, which is not ideal for studying the variables like anxiety. This might have affected the findings of the study. The participants in the study were major. The lengthy survey questionnaire provided to participants may have resulted in fatigue or distraction as they neared the end, impacting the results obtained. There was a lack of equal gender representation in the data, reducing the generalizability of the findings and reducing the representation of other students. This also prevented the researcher to study the gender differences in this particular research.

\section{Recommendations for future study}

Future researchers may use a larger sample size for their analysis, resulting in more meaningful results. The study's sample was not normally distributed, preventing it from being generalized to a wider population. Larger sample size can result in data that is more naturally distributed, allowing researchers to see whether one variable can predict the frequency of other variables. 
More variables like intelligence, achievement, and self-regulation can be studied along with self-efficacy, motivation and anxiety to under a holistic effect of these variables on online academic performance. A qualitative study can also be conducted to better understand the problems that students face in online education and assessment in the Indian context, as well as to contribute to the literature that will be useful to both stakeholders, students, and academic institutions.

\section{CONCLUSION}

Using existing literature in the area, the current study aimed to add to our current understanding of the impact of Self-Efficacy, Motivation, and Anxiety on Online Academic Performance. The introduction of new alternative shifts to online education laid the groundwork for the impact of multiple variables on online academic results. The study found the significant role of anxiety on the online academic performance. The study's findings have significant consequences for the fields of psychology.

\section{REFERENCES}

Alqurashi, E. (2016). Self-Efficacy In Online Learning Environments: A Literature Review. Contemporary Issues in Education Research (CIER), 9(1), 45-52. https://doi.org/10.19030/cier.v9i1.9549

Bates, R., \&Khasawneh, S. (2007). Self-efficacy and college students' perceptions and use of online learning systems. Computers in Human Behavior, 23(1), 175-191.

Chang, C. S., Liu, E. Z. F., Sung, H. Y., Lin, C. H., Chen, N. S., \& Cheng, S. S. (2014). Effects of online college student's Internet self-efficacy on learning motivation and performance. Innovations in Education and Teaching International, 51(4), 366-377. https://doi.org/10.1080/14703297.2013.771429

Dupint-Bryant, P. A. (2004). American Journal of Distance Cognitive Style and SelfEfficacy: Predicting Student Success in. American Journal of Distance Education, 18(1), 39-50. https://doi.org/10.1207/s15389286ajde1801

Hodges, C. B. (2008). Self-efficacy in the context of online learning environments: A review of the literature and directions for research. Performance Improvement Quarterly, 20(3-4), 7-25.

Joo, Y. J., Lim, K. Y., \& Kim, J. (2013). Locus of control, self-efficacy, and task value as predictors of learning outcome in an online university context. Computers and Education, 62, 149-158. https://doi.org/10.1016/j.compedu.2012.10.027

Kuo, Y. C., Walker, A. E., Belland, B. R., Schroder, K. E. E., \&Kuo, Y. T. (2014). A case study of integrating interwise: Interaction, internet self-efficacy, and satisfaction in synchronous online learning environments. International Review of Research in Open and Distance Learning, 15(1), 161-181. https://doi.org/10.19173/irrodl.v15i1.1664

Kuo, Y. C., Walker, A. E., Schroder, K. E. E., \&Belland, B. R. (2014). Interaction, Internet self-efficacy, and self-regulated learning as predictors of student satisfaction in online education courses. Internet and Higher Education, 20, 35-50. https://doi.org/10.1016/j.iheduc.2013.10.001

Peechapol, C., Na-Songkhla, J., Sujiva, S., \&Luangsodsai, A. (2018). An exploration of factors influencing self-efficacy in online learning: A systematic review. International Journal of Emerging Technologies in Learning, 13(9), 64-86. https://doi.org/10.3991/ijet.v13i09.8351

Puzziferro, M. (2008). Online technologies self-efficacy and self-regulated learning as predictors of final grade and satisfaction in college-level online courses. 


\section{Effect of Self-efficacy, Motivation and Anxiety on Online Academic Performance}

International Journal of Phytoremediation, 21(1), 72-89. https://doi.org/10.1080/08923640802039024

Samruayruen, B., Enriquez, J., Natakuatoong, O., \&Samruayruen, K. (2013). Self-regulated learning: A key of a successful learner in online learning environments in Thailand. Journal of Educational Computing Research, 48(1), 45-69.

Shea, P., \&Bidjerano, T. (2010). Learning presence: Towards a theory of self-efficacy, selfregulation, and the development of a communities of inquiry in online and blended learning environments. Computers \& Education, 55(4), 1721-1731.

Shen, D., Cho, M. H., Tsai, C. L., \&Marra, R. (2013). Unpacking online learning experiences: Online learning self-efficacy and learning satisfaction. Internet and Higher Education, 19, 10-17. https://doi.org/10.1016/j.iheduc.2013.04.001

Wang, C. H., Shannon, D. M., \& Ross, M. E. (2013). Students' characteristics, selfregulated learning, technology self-efficacy, and course outcomes in online learning. Distance Education, 34(3), 302-323. https://doi.org/10.1080/01587919.2013.835779

Ajmal, M., \& Ahmad, a. S. (2019). Exploration of anxiety factors among students of distance learning: A case study of Allama Iqbal Open University. Bulletin of Education and Research, 41(2), 67-78. Retrieved from https://files.eric.ed.gov/fulltext/EJ1229454.pdf

Alkış, N., \& Temizel, T. T. (2018). The impact of motivation and personality on academic performance in online and blended learning environments. Educational Technology \&Society, 21(3), 35-47. Retrieved from https://www.researchgate.net/publication/316165852_The_Impact_of_Motivation_a nd_Personality_on_Academic_Performance_in_Online_and_Blended_Learning_Env ironments

Hartnett, M. (2012). Relationships between online motivation, participation, and achievement: more complex than you might think. Journal of Open, Flexible, and Distance Learning, 16(1), 28-41. Retrieved from https://files.eric.ed.gov/fulltext/EJ1079770.pdf

Meral, M., Colak, E., \& Zereyak, E. (2012). The relationship between self-efficacy and academic performance. Procedia - Social and Behavioral Sciences, 46, 1143 - 1146. Retrieved from https://pdf.sciencedirectassets.com/277811/1-s2.0S1877042812X0017X/1-s2.0-S1877042812013936/main.pdf?X-Amz-SecurityToken=IQoJb3JpZ2luX2VjEJb\%2F\%2F\%2F\%2F\%2F\%2F\%2F\%2F\%2F\%2FwEaC XVzLWVhc3QtMSJHMEUCIQCu9\%2F3CWiRTNaPMN\%2FarVFqmUo1C1ULjy UF1uyYR8B\%2BOBgIgW73Ezh

Orhan-Özen, S. (2017). The effect of motivation on student achievement. In The Factors Effecting Student Achievement (pp. 35-56). doi:10.1007/978-3-319-56083-0_3

Peechapol, C., Na-Songkhla, J., Sujiva, S., \& Luangsodsai, A. (2018). An exploration of factors influencing self-efficacy in online learning: a systematic review. iJET, 13(9), 64-86. doi:10.3991/ijet.v13i09.8351

Vitasaria, P., Wahab, M. N., Othman, A., Herawan, T., \& Sinnadurai, S. K. (2010). The relationship between study anxiety and academic performance among engineering students. Procedia Social and Behavioral Sciences, 8, 490-497. Retrieved from https://core.ac.uk/download/pdf/82610739.pdf

Yokoyama, S. (2019). Academic self-efficacy and academic performance in online learning: A mini review. Frontiers in Psychology, 9, 1-4. doi:10.3389/fpsyg.2018.02794

Yusuf, M. (2011). The impact of self-efficacy, achievement motivation, and selfregulated learning strategies on students' academic achievement. Procedia Social and Behavioral Sciences, 15, 2623-2626. Retrieved from 
https://pdf.sciencedirectassets.com/277811/1-s2.0-S1877042811X00071/1-s2.0-

S187704281100704X/main.pdf?X-Amz-Security-

Token=IQoJb3JpZ2luX2VjEJP\%2F\%2F\%2F\%2F\%2F\%2F\%2F\%2F\%2F\%2FwEaC XVzLWVhc3QtMSJHMEUCIH\%2FKmgJx\%2FOOG\%2BedTWo8GX0jrN3otFUE PkxJi48RTwSv9AiEAnpjvwA

Ajmal, M., \& Ahmad, S. (2019). Exploration of Anxiety Factors among Students of Distance Learning: A Case Study of Allama Iqbal Open University. Bulletin of Education and Research, 67-78.

Alkış, N., \& Temizel, T. T. (2018). The Impact of Motivation and Personality on Academic Performance in Online and Blended Learning Environments. Educational Technology \& Society, 35-47.

Asayesh, H., Hosseini, M. a., \& Sharififard, F. (2016). The relationship between selfefficacy and test anxiety among the Paramedical students of Qom University of Medical Sciences. Journal of Advances in Medical Education, 14-21.

Gbollie, C., \& Keamu, H. P. (2017). Student Academic Performance: The Role of Motivation, Strategies, and Perceived Factors Hindering Liberian Junior and Senior High School Students Learning. Education Research International.

Hayat, A. A., Shateri, K., Amini, M., \& Shokrpour, N. (2020). Relationships between academic self-efficacy, learning-related emotions, and metacognitive learning strategies with academic performance in medical students: a structural equation model. BMC Medical Education.

Pascoe, M. C., \& Hetrick, S. E. (2020). The impact of stress on students in secondary school and higher education. International Journal of Adolescence and Youth, 104-112.

Qudsyia, H., \& Putri, M. I. (2017). Self-efficacy and anxiety of National Examination among high school students . Procedia - Social and Behavioral Sciences, 268-275.

Saade, R. G., \& Kira, D. (2017). Anxiety \& Performance in Online Learning. InSITE 2017: Informing Science + IT Education Conference.

Şanl1, C. (2021). The Relation Between Task Value, Test Anxiety and Academic Self Efficacy: A Moderation Analysis in High School Geography Course. Participatory Educational Research, 265-278.

Sharififard, F., \& Asayesh, H. (2020). Motivation, self-efficacy, stress, and academic performance correlation with academic burnout among nursing students. Journal of Nursing and Midwifery Sciences, 88-93.

Yang, X., Zhang, M., Kong, L., \& Wang, Q. (2020). The Effects of Scientific Self-efficacy and Cognitive Anxiety on Science Engagement with the "Question-ObservationDoing-Explanation" Model during School Disruption in COVID-19 Pandemic. Journal of Science Education and Technology.

Yokoyama, S. (2019). Academic Self-Efficacy and Academic Performance in Online Learning: A Mini Review. Frontiers in Psychology, 1-4.

Schwarzer, R., \& Jerusalem, M. (1995). Generalized Self-Efficacy scale. In J. Weinman, S. Wright, \& M. Johnston, Measures in health psychology: A user's portfolio. Causal and control beliefs (pp. 35-37). Windsor, UK: NFER-NELSON.

\section{Acknowledgement}

The author(s) appreciates all those who participated in the study and helped to facilitate the research process.

\section{Conflict of Interest}

The author(s) declared no conflict of interest. 
How to cite this article: D'Souza I. \& Srivastava A. (2021). Effect of Self-efficacy, Motivation and Anxiety on Online Academic Performance. International Journal of Indian Psychology, 9(2), 1932-1959. DIP:18.01.192.20210902, DOI:10.25215/0902.192 